\title{
Taking a look at both sides of the ice: comparison of ice thickness and drift speed as observed from moored, airborne and shore-based instruments near Barrow, Alaska
}

\author{
Andrew R. MAHONEY, ${ }^{1}$ Hajo EICKEN, ${ }^{1}$ Yasushi FUKAMACHI, ${ }^{2}$ Kay I. OHSHIMA, ${ }^{2}$ \\ Daisuke SIMIZU, ${ }^{3}$ Chandra KAMBHAMETTU, ${ }^{4}$ M.V. ROHITH, ${ }^{4}$ Stefan HENDRICKS, ${ }^{5}$ \\ Joshua JONES ${ }^{1}$ \\ ${ }^{1}$ Geophysical Institute, University of Alaska Fairbanks, Fairbanks, AK, USA \\ E-mail: mahoney@gi.alaska.edu \\ ${ }^{2}$ Institute of Low Temperature Science, Hokkaido University, Sapporo, Japan \\ ${ }^{3}$ National Institute of Polar Research, Tachikawa, Japan \\ ${ }^{4}$ University of Delaware, Newark, DE, USA \\ ${ }^{5}$ Alfred Wegener Institute Helmholtz Centre for Polar and Marine Research, Bremerhaven, Germany
}

\begin{abstract}
Data from the Seasonal Ice Zone Observing Network (SIZONet) acquired near Barrow, Alaska, during the 2009/10 ice season allow novel comparisons between measurements of ice thickness and velocity. An airborne electromagnetic survey that passed over a moored Ice Profiling Sonar (IPS) provided coincident independent measurements of total ice and snow thickness and ice draft at a scale of $10 \mathrm{~km}$. Once differences in sampling footprint size are accounted for, we reconcile the respective probability distributions and estimate the thickness of level sea ice at $1.48 \pm 0.1 \mathrm{~m}$, with a snow depth of $0.12 \pm 0.07 \mathrm{~m}$. We also complete what we believe is the first independent validation of radar-derived ice velocities by comparing measurements from a coastal radar with those from an under-ice acoustic Doppler current profiler (ADCP). After applying a median filter to reduce high-frequency scatter in the radar-derived data, we find good agreement with the ADCP bottom-tracked ice velocities. With increasing regulatory and operational needs for sea-ice data, including the number and thickness of pressure ridges, coordinated observing networks such as SIZONet can provide the means of reducing uncertainties inherent in individual datasets.
\end{abstract}

KEYWORDS: aerogeophysical measurements, Arctic glaciology, remote sensing, sea ice, sea-ice dynamics

\section{INTRODUCTION}

With ongoing retreat and thinning of Arctic sea ice (Wang and Overland, 2009; Stroeve and others, 2012) and growing commercial interest in resource extraction and marine navigation (Arctic Council, 2009; Schmidt, 2011), there is an increasing demand for observational data of ice thickness and velocity. Although a growing number of pan-Arctic and regional sea-ice thickness datasets are becoming publicly available (e.g. Kurtz and others, 2009; Laxon and others, 2013), their usefulness for regulatory and operational purposes is limited by spatial resolution and error characteristics. Altimetry-derived ice thicknesses suffer from large errors, primarily due to uncertainties in the snow depth and the densities of the sea ice and snow. Kwok and Cunningham (2008) estimate that the uncertainties in densities alone account for $10-20 \%$ of the variance in Arctic sea-ice thickness calculated using Ice Cloud and land Elevation Satellite (ICESat) data. Moreover, the spatial resolution of these satellite-derived products is too coarse to resolve pressure ridges, which comprise the thickest elements of the ice cover.

Airborne and submarine platforms provide the best means of obtaining sea-ice thickness data at intermediate spatial scales that sample enough ice to obtain useful thickness statistics while also resolving individual ridges. Airborne thickness surveys use altimetric techniques similar to those used from space or employ a combination of altimetry and electromagnetic induction (Haas and others, 2009 , 2010) to calculate total snow and ice thickness without requiring knowledge of their densities. Upwardlooking sonar on naval submarines travelling beneath the ice has provided a wealth of data on sea-ice thicknesses dating back to the early 1970s (Thorndike and others, 1975), but in recent years it has become more common to use moored Ice Profiling Sonars (IPSs) to observe the ice as it passes overhead (e.g. Melling and others, 1995; Hansen and others, 2013). Submarine methods also use a form of altimetry to determine ice thickness, but instead of measuring freeboard they measure the draft of ice and are therefore less sensitive to uncertainties in the densities of snow, ice and water and to snow depth (Forsström and others, 2011).

The measurement of ice velocity is essential for a proper analysis of ice thickness data collected by IPSs and it is common practice to deploy acoustic Doppler current profilers (ADCPs) alongside each IPS to measure the drift of ice. Ice velocity is also a key constraint, together with ice thickness, for the design of Arctic offshore structures (ISO, 2010). Observation of ice motion may be either Eulerian (as in the case of a mooring measuring ice drift at a fixed point) or Lagrangian (such as using a GPS-tracked buoy to record the path of an ice floe). Here we focus on Eulerian measurements of ice velocity, which can also be derived at a grid of points using sequences of images of sea ice (e.g. Fowler, 2003; Kwok and others, 2003). 


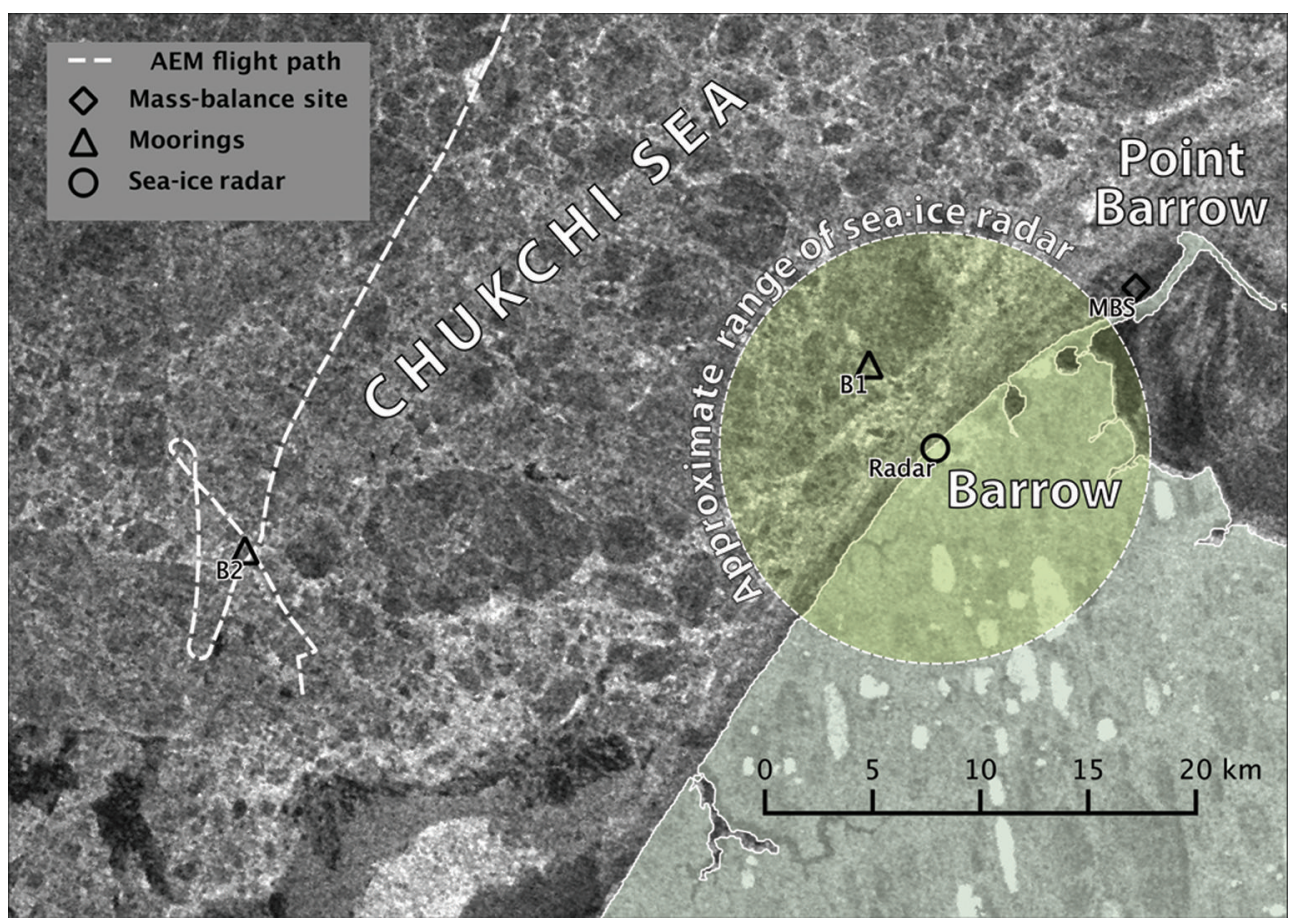

Fig. 1. AEM flight path over mooring B2 on 12 April 2010 near Barrow, Alaska. Also shown are the locations of mooring B1, an ice massbalance site (MBS) and the approximate range of a coastal sea-ice radar system installed on a building in Barrow. The background is a Wide Swath Envisat ASAR image acquired 1 hour after the AEM flight passed over mooring B2.

In this paper, we combine data collected as part of the Seasonal Ice Zone Observing Network (SIZONet; sizonet. org) to make novel comparisons between coincident and co-located observations of sea ice from above and below. Using airborne electromagnetic (AEM) data collected along a flight that passed over a moored IPS, we compare two completely independent measurements of the local ice thickness distribution around the mooring. This comparison also allows us to estimate the thickness of the snow on top of

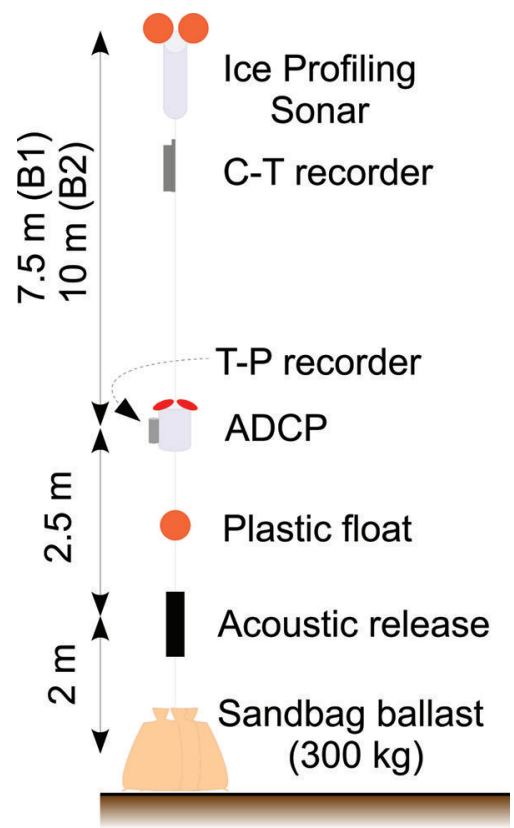

Fig. 2. Configuration of SIZONet moorings deployed near Barrow in 2009/10. Distances indicate approximate rope lengths between mooring components. the ice. We also make a comparison between ice velocities recorded by an upward-looking ADCP and those determined from sequences of imagery acquired by a coastalbased radar system. To our knowledge, this is the first such validation of surface radar-derived ice velocities and it demonstrates the suitability of such systems for real-time ice and hazard monitoring in the Arctic coastal regions.

\section{DATASETS AND METHODS}

\subsection{Ice draft and velocity measurements from under- ice moorings}

Two moorings (B1 and B2) were deployed near Barrow, Alaska, USA, as part of SIZONet (Fig. 1). Mooring B1 was deployed at $71.32698^{\circ} \mathrm{N}, 156.87663^{\circ} \mathrm{W}$ on 5 August 2009 and retrieved on 29 July 2010 . Mooring B2 was deployed at $71.23471^{\circ} \mathrm{N}, 157.65271^{\circ} \mathrm{W}$ on 7 August 2009 and retrieved on 29 July 2010 . These moorings each comprised an ASL Environmental Science Ice Profiler IPS and a Teledyne RDI Workhorse Sentinel ADCP as well as a Seabird SBE-37 conductivity-temperature (C-T) recorder and a Seabird SBE-39 temperature-pressure (T-P) recorder (Fig. 2). The IPSs are used to measure the draft of the sea ice passing overhead while the ADCPs measure current velocity profile of the overlying water column and, of particular relevance here, the velocity of the ice through bottom tracking.

The calculation of ice draft from raw IPS data is an involved process, described in detail by Melling and others (1995). In brief, the distance from the sonar to the ice or open-water surface is determined from the travel time of echoes, with adjustments made for instrument tilt. Corrections for sound-speed variations over time are made by identifying open water above the sonar and reconciling the measured echo travel time with the depth determined from 
an onboard pressure sensor. Through this approach, the draft of the level ice can be measured to an estimated accuracy and precision of $\pm 0.05 \mathrm{~m}$ (Fukamachi and others, 2006). Ice draft measurements are made at $1 \mathrm{~s}$ intervals.

A moored IPS generates a time series of ice draft at a fixed location as the sea ice drifts overhead. Since the drift velocity of the ice is not constant over time, these data cannot be used to derive distance-referenced probability distributions. It is therefore necessary to transform the time series into a pseudo-spatial series using ice velocity data. In our case we use ice velocities calculated from the ADCP bottom track data. The ice velocity is determined from the Doppler shifts of acoustic signals returned from the bottom of the ice. This is similar to the method used to determine the water velocity, but a separate longer-pulse signal is used to achieve accuracies of a few $\mathrm{mm} \mathrm{s}^{-1}$ (Gordon, 1996).

The bottom track data are recorded every $15 \mathrm{~min}$ and so must be interpolated to match the $1 \mathrm{~s}$ time series recorded by the IPS. Each interpolated velocity measurement thus represents an effective sampling distance for each ice draft measurement. We then use a cubic spline interpolation to create a regularly spaced pseudo-spatial series of ice draft with $1 \mathrm{~m}$ spacing, approximately matching the footprint of the sonar beam on the underside of the ice (Williams and others, 2008). The measurement of ice draft can be related to ice thickness by invoking Archimedes' principle, with the total weight of the ice and snow equal to the weight of the water displaced. If we assume that the ice at each measurement is in isostatic equilibrium, then this can be expressed as

$$
\rho_{\mathrm{i}} Z_{\mathrm{i}}+\rho_{\mathrm{s}} Z_{\mathrm{s}}=\rho_{\mathrm{w}} D
$$

where $\rho_{\mathrm{i}}, \rho_{\mathrm{s}}$ and $\rho_{\mathrm{w}}$ are the densities of ice, snow and water, respectively. $Z_{\mathrm{i}}$ and $Z_{\mathrm{s}}$ are the thicknesses of ice and snow, respectively, and $D$ is the ice draft.

\subsection{Airborne electromagnetic (AEM) ice thickness measurements}

AEM sounding uses electromagnetic (EM) induction to determine the distance from the towed instrument, known as an EM-bird, to the water surface (Haas and others, 2009, 2010). The technique involves emitting a primary EM field (in this case at $4.09 \mathrm{kHz}$ ), which induces a secondary field in the conductive sea water. Using a one-dimensional model in which the sea-water and sea-ice conductivities are specified (Pfaffling and others, 2007), the distance to the underside of the ice can be determined from the relative strength of the in-phase component of the secondary field. At the same time, the distance to the upper surface of the ice (or snow if present) is measured using a laser altimeter mounted in the EM-bird. The combined thickness of snow and sea ice is determined by subtracting these two distances (Fig. 3). In comparison with field measurements, this technique is found to have an accuracy of better than $0.1 \mathrm{~m}$ over level ice (Haas and others, 2009).

In April 2010, two AEM flights were made over the sea ice near Barrow as part of SIZONet activities. On 12 April 2010, the flight path passed twice over mooring B2 (Fig. 1). A helicopter was used for these flights, allowing us to make controlled, tight turns over the mooring location. The EMbird was flown at an altitude of $\sim 15 \mathrm{~m}$, giving an effective sampling footprint of $\sim 70 \mathrm{~m}$. Each AEM measurement is thus a mean value of ice and snow thickness over this area. The EM-bird will therefore tend to underestimate the maximum

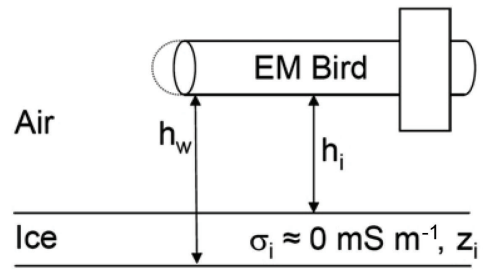

Water $\sigma_{\mathrm{w}} \approx 2500 \mathrm{mS} \mathrm{m}^{-1}, \mathrm{z}_{\mathrm{w}}=\infty$

Fig. 3. From Haas and others (2009). Principle of AEM thickness sounding, using a bird with transmitter and receiver coils and a laser altimeter. Ice thickness $Z_{i}$ is obtained from the difference between measurements of the bird's height above the water and ice surface, $h_{\mathrm{w}}$ and $h_{\mathrm{i}}$, respectively.

thickness of ice ridges, though it can be expected to give an accurate measure of the overall ice volume (Pfaffling and others, 2007).

\subsection{Gridded ice velocities from coastal sea-ice radar data}

The University of Alaska Fairbanks (UAF) has operated a coastal sea-ice radar discontinuously since the 1970s (Shapiro and Metzner, 1989; Mahoney and others, 2007; Druckenmiller and others, 2009; Jones, 2013; Rohith and others, 2013). Data from the current system are available in near real time from http://seaice.alaska.edu/gi/observatories /barrow_radar. Figure 4 shows an image from the radar on 12 April 2010 coinciding with the Envisat Advanced Synthetic Aperture Radar (ASAR) image shown in Figure 1. The coastal radar has a considerably lower grazing angle than space-based systems and is reliant on rough surfaces with higher local incidence angles to act as natural reflectors. The coastal radar is therefore mostly sensitive to ridges and floe edges, with little or no energy returned from areas of level ice in between. As a result, images from the coastal radar often contain 'empty' regions without features that can be tracked through commonly used techniques based upon cross-correlation of image pairs. To overcome these challenges, we use a combination of dense and sparse optical flow methods to generate gridded ice velocities (Rohith and others, 2013)

The radar data are recorded in range-azimuth space with 512 samples per range line and up to 4096 lines per rotation. The calculation of velocity in physical units requires accurate geolocation of the radar imagery. We determined the correct range resolution and orientation of the imagery using linear ground control features such as pipelines, roads and snow fences that were recognizable in both the radar imagery and high-resolution satellite data available through the Geographic Information Network of Alaska (GINA). At a nominal range setting of 6 nautical miles, we determined the range resolution to be $21.5 \pm 0.5 \mathrm{~m}$, which is the pixel size chosen for reprojection of the data to a Cartesian plane. The radar system records images every 120 rotations, which at a rotation speed of $\sim 0.5 \mathrm{~Hz}$ corresponds to $\sim 4 \mathrm{~min}$ between images although this interval is variable due to small changes in rotation speed of the radar antenna. Since the file creation times for each radar image are only preserved to an accuracy of $1 \mathrm{~min}$, it is therefore difficult to precisely determine the time 


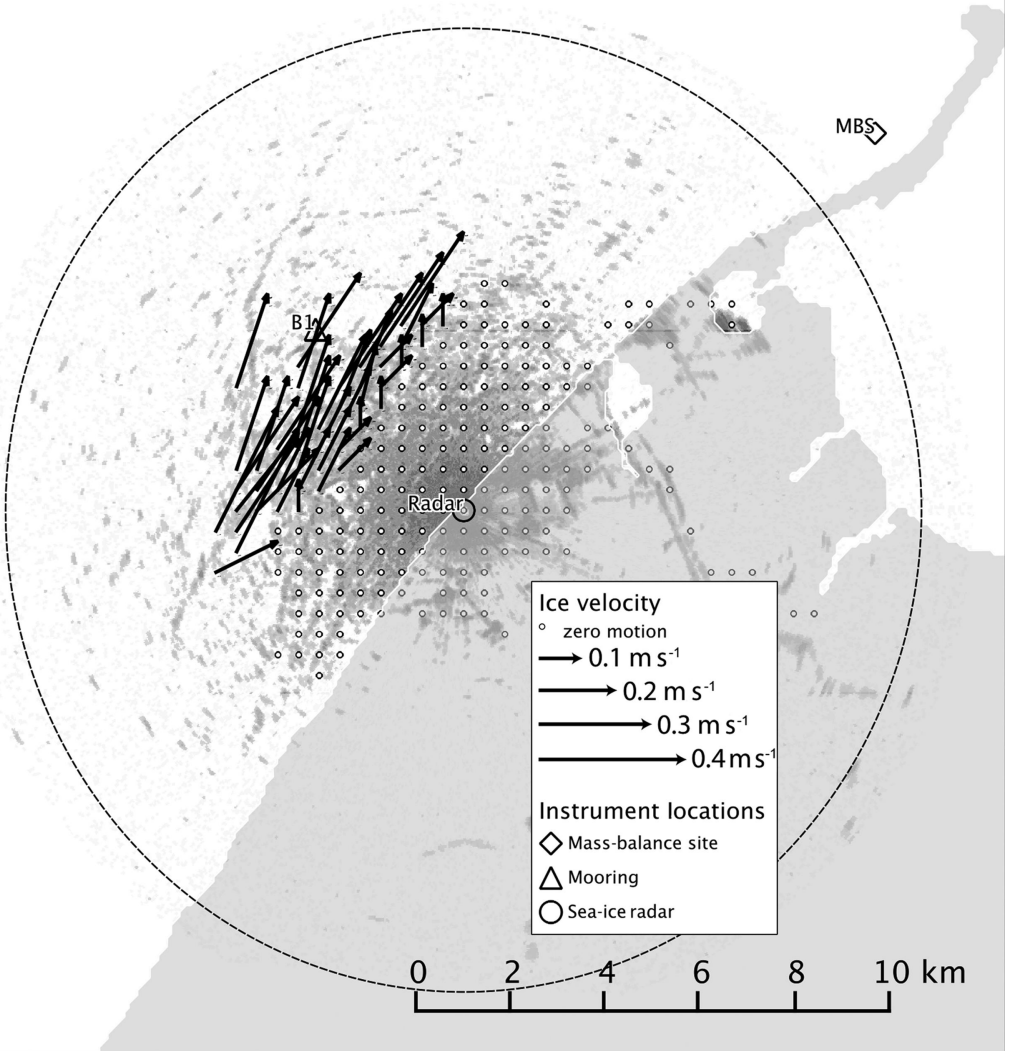

Fig. 4. Coastal radar image acquired at 21:25 on 12 April 2010 (UTC), coincident with the Envisat ASAR image in Figure 1. Vectors show ice velocities determined from consecutive images.

interval over which motion is observed. However, over the whole record for the 2009/10 season, we calculate an average interval between consecutive images of $231 \pm 9 \mathrm{~s}$. Together, these uncertainties in spatial scale and time interval amount to a $5 \%$ error in the radar-derived velocities.

The velocity vectors shown in Figure 4 are calculated on a $20 \times 20$ pixel $(438 \mathrm{~m} \times 438 \mathrm{~m})$ grid and have been median-filtered in time to remove erroneous values (this procedure is discussed in more detail in Section 3). Gridpoints with zero velocity are shown by white dots and indicate the extent of landfast ice at the time of data acquisition. Gridpoints where no velocity measurement could be determined are blank. Velocity determination typically fails due to one of three causes: (1) a lack of reflectors; (2) excessive ice motion; or (3) rapid changes in reflector orientation or shape due to ice movement or deformation. For the purposes of comparing radar-derived ice velocities with the bottom track data recorded by the $\mathrm{ADCP}$, we calculate the mean velocity recorded at the four gridpoints surrounding mooring B1.

Table 1. Time, closest distance and coincident measurements for AEM overpasses 1 and 2

Overpass Time (UTC) Spatial offset Ice + snow $\quad$ Ice draft

$\mathrm{m} \quad \mathrm{m}$

\begin{tabular}{lllll}
\hline 1 & $20: 26: 50$ & 345 & 1.54 & 4.93 \\
2 & $20: 38: 05$ & 269 & 1.96 & 3.99
\end{tabular}

\section{RESULTS}

\subsection{Ice thickness over mooring B2}

Figure 5 shows the path of the AEM flight on 12 April 2010 (in white) over mooring B2 together with a pseudo-track of ice motion (in gray) derived by integrating the bottom track velocity recorded by the ADCP forward and backwards in time from the time of the AEM overpass. The continuous white lines indicate portions of the flight made at measurement altitude within a $10 \mathrm{~km}$ radius of the mooring (shown by the black dashed circle). The white dots indicate the calculated 6 hourly positions along the pseudo-track. The helicopter made two separate overpasses, which are indicated by the labeled arrows. Table 1 lists the time and distance of the closest point on each overpass together with the AEM-derived ice thickness and the IPS-measured ice draft at the times. The background is the Envisat ASAR image shown in Figure 1, which was acquired at 21:26:59 UTC (coordinated universal time) on 12 April, just 1 hour after the first overpass. The black cross indicates the location of ice that was at the mooring at the time of overpass 1 , based on the pseudo-track data.

Table 1 shows significant differences between the coincident AEM and IPS measurements at the time of each overpass. In both cases the IPS-measured draft is greater than the AEM-measured combined snow and ice thickness. In some cases such differences can be accounted for by the larger sampling footprint of the EM-bird, if there happened to be a narrow ridge keel above the IPS at the time of the overpass, the thickness of which would be underestimated in the AEM data. However, examination of the IPS before and after each overpass indicates this is not the case. 


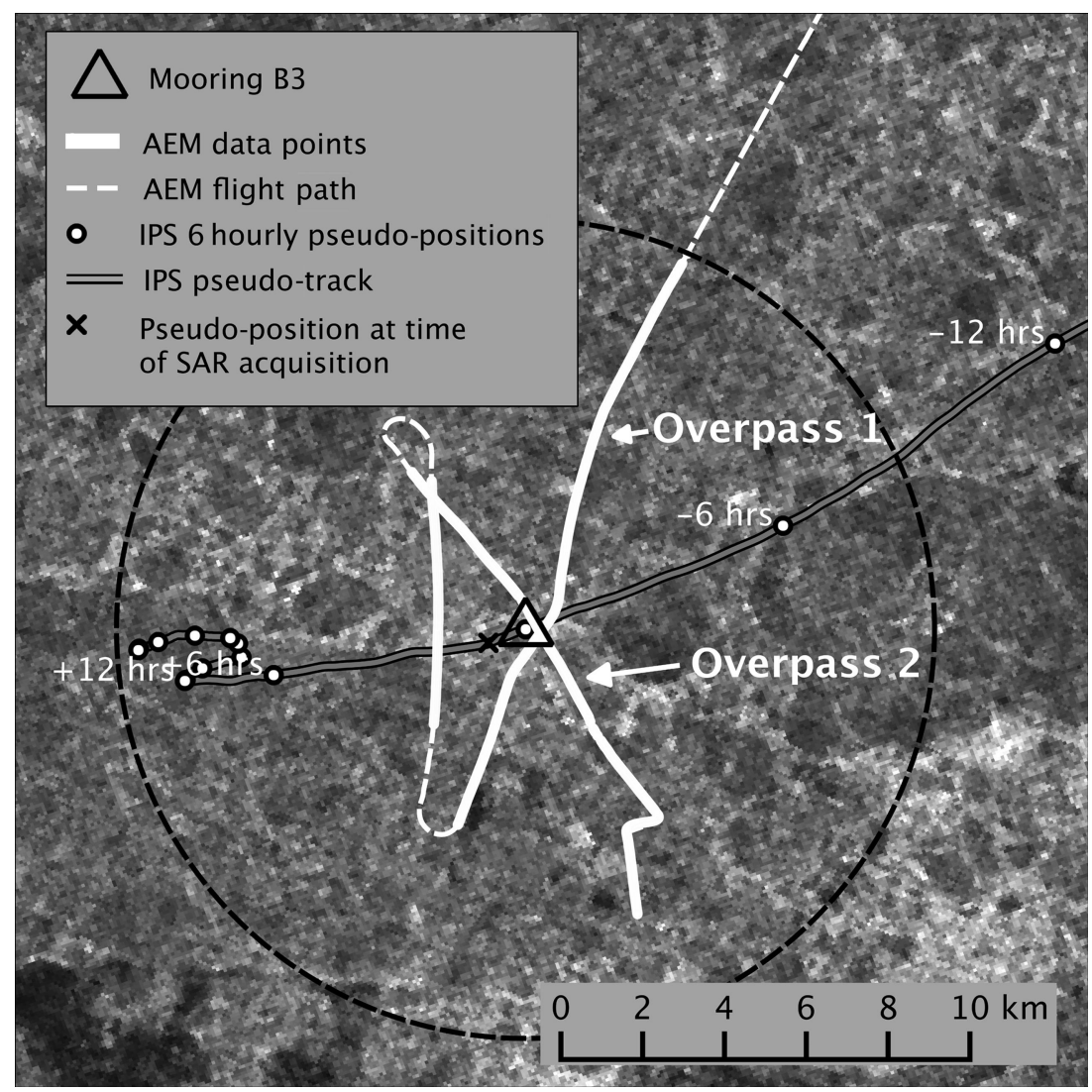

Fig. 5. Map showing the AEM flight path over mooring B2. The gray line indicates a pseudo-track of ice drift calculated by integrating the bottom track velocity over time. White dots indicate the 6 hourly pseudo-positions of the ice before and after the overpass. Only those at \pm 6 and 12 hours are labeled, to reduce clutter in the figure. The black cross indicates ice that was at the mooring at the time of overpass 1.

Instead, it is more likely the difference is due to the spatial offset between the actual measurement locations. This is supported by the SAR image in Figure 5, which shows high backscatter in the region of the mooring at the time of the overpass (marked by black cross), indicating rough, heterogeneous ice.

Neither of the overpasses was aligned with the drift of ice at the time, which means it is not feasible to attempt to colocate the measurements more accurately. We therefore compare AEM and IPS measurements by calculating their probability distributions using all data that fall within $10 \mathrm{~km}$ of mooring B2 (indicated by the black dashed circle in Fig. 5). Figure 6 shows the distributions of AEM-derived ice and snow thickness and IPS-derived ice draft, binned into $0.05 \mathrm{~m}$ intervals. Both distributions have pronounced modes, which represent the thickness and draft of level undeformed ice. The AEM data indicate a modal combined thickness of ice and snow of $1.6 \pm 0.025 \mathrm{~m}$ while the IPS data show a modal ice draft of $1.35 \pm 0.025 \mathrm{~m}$. These values and their relationship with density and snow depth are discussed in more detail below.

\subsection{Ice velocities near Barrow during 2009/10 winter season}

A comparison of radar-derived and ADCP bottom-tracked ice velocities was carried out for mooring B1 for the period 1 November 2009 to 30 June 2010 (Fig. 7). We binned the radar-derived values every $15 \mathrm{~min}$ to match the sampling interval of the ADCP. We have also excluded data from periods with a significant open-water fraction and when the instrument tilt exceeded $20^{\circ}$. The presence of open water can be inferred from increased magnitude and variability of the bottom track error recorded by the ADCP due to the presence of surface waves (Belliveau and others, 1990). We applied a 2 hour running mean to the bottom track error values and discarded data from periods with error values greater than $0.1 \mathrm{~m} \mathrm{~s}^{-1}$.

The radar-derived velocities show significant scatter and that the optical flow algorithm tends to overestimate ice speed as compared to bottom-tracked ice velocities. However, we see considerably better agreement when we

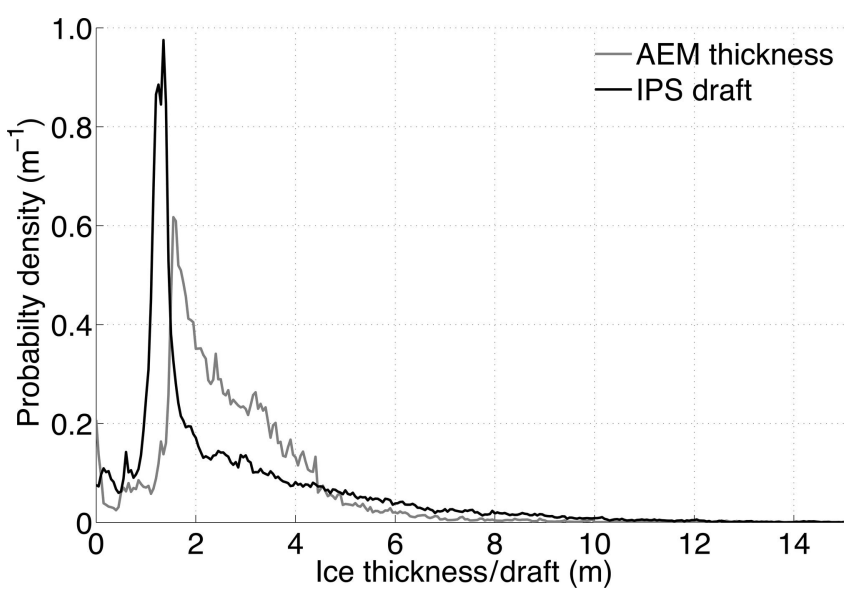

Fig. 6. Probability distribution of combined ice and snow thickness (AEM) and ice draft (IPS) derived from all measurements within $10 \mathrm{~km}$ of mooring B2. 


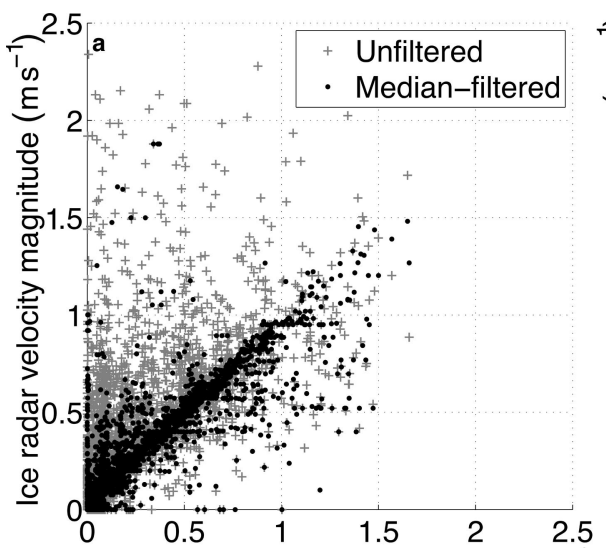

Bottom track velocity magnitude $\left(\mathrm{ms}^{-1}\right)$
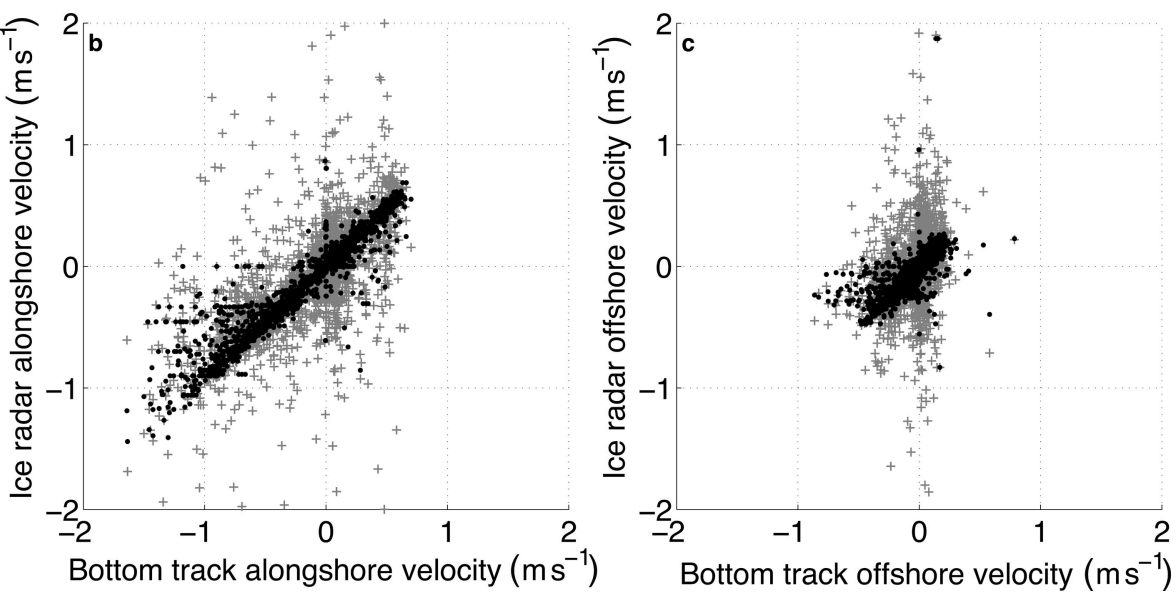

Bottom track offshore velocity $\left(\mathrm{ms}^{-1}\right)$

Fig. 7. Scatter plots comparing ADCP- and radar-derived ice velocities for winter 2009/10: (a) velocity magnitude; (b) alongshore velocity component; (c) offshore velocity component.

apply a 2 hour running median filter to the radar-derived data, with tighter clustering around the line $y=x$ and an improvement in the root-mean-square $(\mathrm{rms})$ difference in velocity magnitudes from $0.24 \mathrm{~m} \mathrm{~s}^{-1}$ to $0.12 \mathrm{~m} \mathrm{~s}^{-1}$. The close agreement in both alongshore and offshore components indicates that both datasets are well aligned geographically.

Examining the radar-derived ice velocities and ADCP bottom-tracked velocities as time series (Fig. 8) confirms the overall good agreement between these two independent observations of ice motion while also allowing closer scrutiny of those occasions when the results differ. The gray boxes indicate periods of open water inferred from the bottom track error as described above. It is clear that these periods correspond to the highest velocities and also coincide with many of the gaps in the coastal radar velocity record. Examination of the radar imagery during these data gaps reveals an absence of reflectors over the mooring site. We remind the reader that, due to the insensitivity of the coastal radar system to areas of smooth ice, the absence of reflectors in the imagery does not necessarily imply an absence of ice on the ocean, but in those cases where there is sufficient daylight we are able to confirm the presence of open water through examination of images from the Barrow sea-ice webcam (http://seaice.alaska.edu/gi/observatories/ barrow_webcam), which is co-located with the radar. Despite the gaps in the radar velocity record, there are
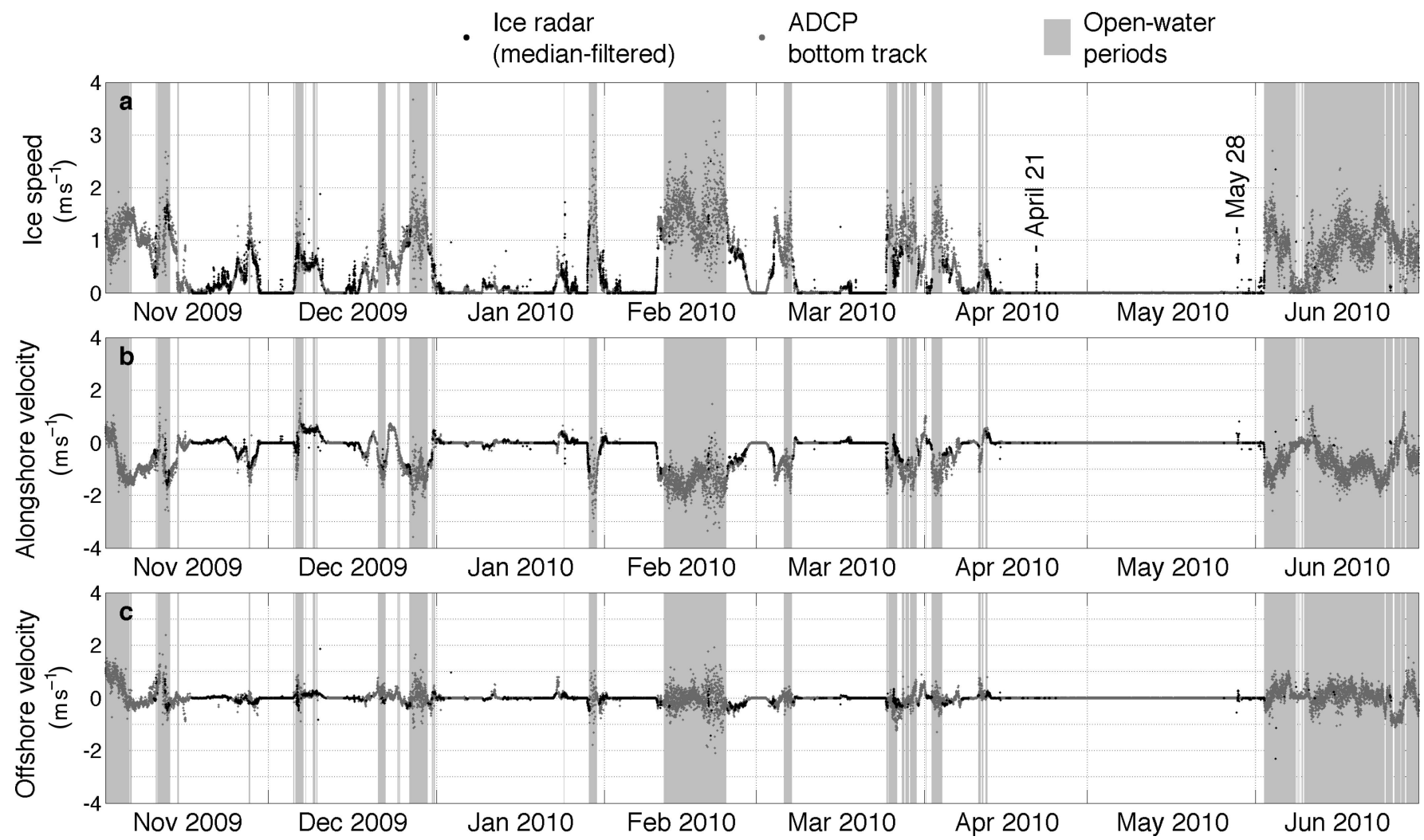

Fig. 8. Time series of (a) ice velocity magnitude and (b) alongshore and (c) offshore components derived from the ice radar (black dots) and ADCP bottom track data (gray dots). Open-water periods are shown by gray shading. 


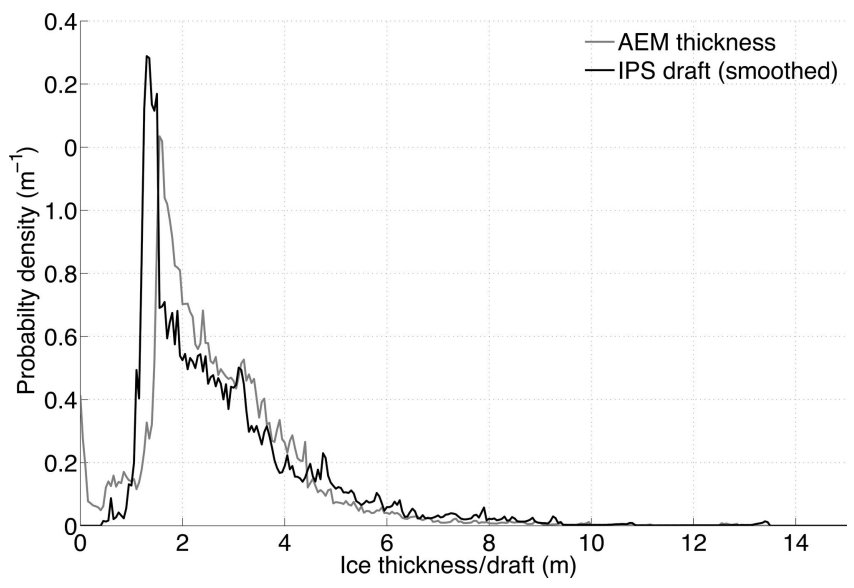

Fig. 9. Probability distribution of combined ice and snow thickness (AEM) and $70 \mathrm{~m}$ boxcar smoothed ice draft (IPS) derived from all measurements within $10 \mathrm{~km}$ of mooring B2.

occasions when the radar was able to detect and track ice during periods of inferred open water. For these cases the overall rms difference between the bottom track data and median-filtered radar-derived ice velocity is $0.48 \mathrm{~m} \mathrm{~s}^{-1}$, with a tendency for the radar to underestimate the ice velocity relative to the $\mathrm{ADCP}$.

\section{DISCUSSION}

\subsection{Reconciling thickness and draft measurements}

To our knowledge, the AEM flight that twice passed within $350 \mathrm{~m}$ of mooring B2 allowed the first direct comparison between airborne and submarine measurements of ice thickness at a scale larger than that of an individual floe (e.g. Doble and others, 2011). To compare AEM and IPS data it is important to understand the measurements that each instrument makes and how these relate to each other. Primarily it is important to recall that the EM-bird measures the combined thickness of snow and ice while the IPS measures just the draft of the ice. Rearranging Eqn (1) and substituting a thickness-weighted mean density of snow and ice, $\rho^{*}$, we can express the expected relationship between the AEM and IPS measurements as

$$
\left(Z_{\mathrm{i}}+Z_{\mathrm{s}}\right)=\frac{\rho_{\mathrm{w}}}{\rho^{*}} D
$$

where

$$
\rho^{*}=\frac{\rho_{\mathrm{i}} Z_{\mathrm{i}}+\rho_{\mathrm{s}} Z_{\mathrm{s}}}{Z_{\mathrm{i}}+Z_{\mathrm{s}}}
$$

At the time of the AEM overpass, the temperature and salinity at mooring $\mathrm{B} 2$ were $-1.686^{\circ} \mathrm{C}$ and 31.69 , respectively, which yields a sea-water density, $\rho_{\mathrm{w}}$, of $1025 \mathrm{~kg} \mathrm{~m}^{-3}$. Substituting this and the modal values derived from our measurements shown in Figure $6\left(Z_{i}+Z_{s}=1.6 \pm 0.025 \mathrm{~m}\right.$ and $D=1.35 \pm 0.025 \mathrm{~m}$ ), we derive a value of $\rho^{*}$ of $860 \pm$ $30 \mathrm{~kg} \mathrm{~m}^{-3}$. Assuming a sea-ice density of $910 \pm 20 \mathrm{~kg} \mathrm{~m}^{-3}$ (Timco and Frederking, 1996) and a snow density of $300 \pm 100 \mathrm{~kg} \mathrm{~m}^{-3}$, taken from data for March reported by Warren and others (1999), we can use Eqn (3) to estimate that the level ice in the vicinity of mooring B2 on 12 April 2010 was $1.48 \pm 0.09 \mathrm{~m}$ thick, with a snow depth of $0.12 \pm 0.09 \mathrm{~m}$. Here we assume the uncertainties are normally distributed and uncorrelated, and we use the
Gaussian method to propagate errors. Although the largest uncertainty, both in relative and absolute terms, is that for snow depth, the uncertainty in the value of $\rho^{*}$ has the biggest effect on the derived values. This in turn is dependent on the uncertainties in the densities of water and ice and our ability to determine the modes in the AEM and IPS data.

For comparison, sea ice at the UAF mass-balance site (Fig. 1) on 12 April was $1.24 \mathrm{~m}$ thick and the snow depth measured by three sonic altimeters ranged between 0.29 and $0.43 \mathrm{~m}$, with a mean of $0.35 \mathrm{~m}$. Although these values are not in direct agreement, the differences in ice thickness and snow depth are consistent with each other. Although measurements of snow on drifting sea ice are rare, we expect snow to be thicker on landfast ice along the Alaska Chukchi Coast than on drifting ice offshore. Shorefast ice near Barrow is typically among the first ice to form in the Chukchi Sea and collects snow drifting in from a broad catchment carried by prevailing northeasterly winds. In contrast, these same prevailing winds create a semi-persistent coastal polynya at the seaward edge of the landfast ice (Eicken and others, 2006; Mahoney and others, 2012) that may reduce the amount of snow advected onto drifting sea ice downwind. With less snow to insulate the ice surface, the offshore ice can therefore be expected to be thicker.

Closer examination of the two distributions (Fig. 6) shows that they differ not only in the position of their modes, but also in the shape of the tail, most noticeably for ice thicknesses less than $4 \mathrm{~m}$. This difference cannot be accounted for by a simple isostatic assumption, so instead we consider the differing footprints of the two instruments. To better match the footprints of the two instruments, we applied a $70 \mathrm{~m}$ boxcar smoothing filter to the IPS data. This smoothing changes the shape of the tail of the IPS draft distribution to more closely resemble that of the AEM data (Fig. 9). A Gaussian filter was also tried, but resulted in a poorer fit. Having reconciled the sampling footprints of the IPS and AEM, we then applied a stretching to the smoothed IPS draft distribution that minimized the rms difference between it and the AEM distribution. Using this approach we find a conversion factor from ice draft to total thickness of $1.20 \pm 0.01 \mathrm{~m}$ (Fig. 10), which corresponds to a distribution-wide mean value of $\rho^{*}$ of $850 \pm 0.30 \mathrm{~kg} \mathrm{~m}^{-3}$. Within $10 \mathrm{~km}$ of mooring B2, the mean thickness of ice and snow measured by the EM-bird is $2.66 \mathrm{~m}$. Our mean value $\rho^{*}$ therefore corresponds to a mean ice thickness of $2.40 \pm 0.14 \mathrm{~m}$ and a mean snow depth of $0.26 \pm 0.14 \mathrm{~m}$.

Although there is good agreement between the modes of the AEM and smoothed, shifted IPS (Fig. 10), there are differences in the two distributions that warrant further comment. We expect the distributions to differ simply because the AEM flight path and IPS pseudo-track do not overlap and the two sensors did not observe exactly the same ice. We believe this explains why the AEM data show a greater amount of thin ice $(<1 \mathrm{~m})$ than the IPS data. There are also differences in the tail such that the AEM data indicate more ice between 1.4 and $4.0 \mathrm{~m}$, and less ice $>4 \mathrm{~m}$, than the IPS data. This may derive from the different sampling areas, but it also probably indicates that deformed ice must be treated differently than level ice when it comes to assumptions concerning the effective mean ice density or electrical conductivity. This is discussed further in Section 5. The relative over- and under-observation of ice thinner and thicker than $\sim 4 \mathrm{~m}$, respectively, might also be explained if 


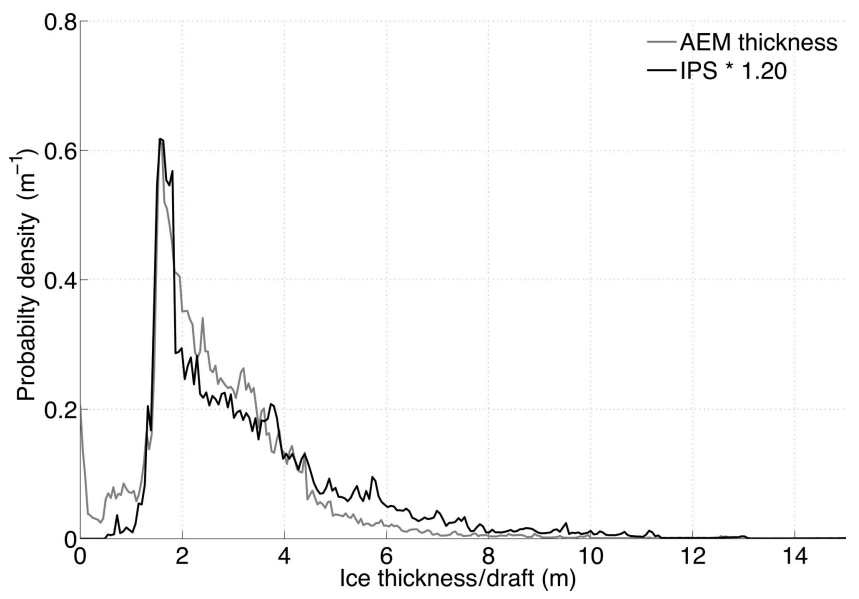

Fig. 10. Probability distribution of combined ice and snow thickness (AEM) and $70 \mathrm{~m}$ boxcar smoothed, isostatically adjusted ice draft (IPS*1.20) derived from all measurements within $10 \mathrm{~km}$ of mooring B2.

the sensitivity of the EM-bird was reduced to the noise level of the receiver at this equivalent range. However, theoretical considerations of the EM response show that signal-to-noise ratios are not critical until a range of 30-35 m, corresponding to an ice thickness of $15-20 \mathrm{~m}$ at a survey altitude of $15 \mathrm{~m}$.

\subsection{Coastal ice motion observed from above and below}

Figure 8 shows the variability of ice motion at one point in the coastal zone near Barrow over a full ice season. Zero ice motion indicates the ice above the mooring was landfast. The record shows landfast ice forming over the mooring as early as mid-November, with several attachment and detachment events occurring throughout the year. In general, the periods of landfast ice lengthen over the course of the year before final break-up over the mooring around the beginning of June. Both the ADCP and the coastal radar system identify each cessation and recommencement of ice motion, though in some cases the occurrence of landfast ice coincides with data gaps in the radar-derived ice velocity record (e.g. the latter part of April and most of May). Examination of the radar imagery on these occasions indicates these gaps are due to a lack of reflectors over the mooring. However, the presence of ice can be confirmed from the presence of stationary reflectors in the neighborhood. On other occasions, the radar data show apparent ice motion while the ADCP data continue to indicate landfast ice (e.g. 21 April and 28 May). In these cases we find that the ice motion algorithm was confused by the passage of snow squalls and migrating birds.

In identifying the onset of ice motion at the end of landfast periods, the ADCP and radar-derived ice velocity records provide accurate timings of detachment events. The detachment of landfast ice represents a significant hazard to anyone on the ice when it begins to move. At the same time, such events are important to communities along the Alaska Chukchi Coast during the spring whaling season, since any open water created provides access to hunt the whales migrating north along the coast (George and others, 2004; Druckenmiller and others, 2010). Previous studies of coastal ice dynamics using surface radars have noted that it may be possible to detect precursor events leading up to detachments. Shapiro and Metzner (1989) and Mahoney and others (2007) report the occurrence of 'flickering' in the radar imagery prior to breakout events. Rohith and others (2013) have taken this further to develop an algorithm based on Hidden Markov Models that has successfully detected some breakout events based on 'hidden' characteristics of the gridded flow field. A more detailed study of landfast ice detachments, including an analysis of ice deformation from radar-derived gridded ice velocities, is provided by Jones (2013).

\section{CONCLUSIONS}

By assembling a number of different SIZONet datasets acquired in the 2009/10 ice season near Barrow, we have been able to perform unique comparisons between coincident measurements of sea ice from above and below. Once differences in sampling footprint size between the EMbird and the IPS had been accounted for, the probability distributions of ice thickness and draft within $10 \mathrm{~km}$ of mooring B2 on 12 April 2010 could be reconciled by assuming mean density of the combined snow and ice cover. Moreover, this value can be used to estimate the relative proportions of snow and ice comprising the thickness measured by the EM-bird. Assuming sea-ice and snow densities of $910 \pm 20 \mathrm{~kg} \mathrm{~m}^{-3}$ and $300 \pm 10 \mathrm{~kg} \mathrm{~m}^{-3}$, respectively, we estimate the thickness of level sea ice near mooring B2 at $1.48 \pm 0.09 \mathrm{~m}$, with a snow depth of $0.12 \pm 0.09 \mathrm{~m}$. Applying this method to the whole thickness distribution, including thick deformed ice, we estimate a mean ice thickness and snow depth of $2.40 \pm 0.14 \mathrm{~m}$ and $0.26 \pm 0.14 \mathrm{~m}$, respectively. However, by including deformed ice in the latter calculation, we may be overestimating the effective mean density of the ice, which in turn will lead to an underestimation of ice thickness and an overestimation of snow depth.

The inhomogeneous composition of deformed ice creates significant uncertainty in the thickness of ridges derived from both IPS and AEM measurements. Pressure ridges are not necessarily in isostatic equilibrium on a point-to-point basis, and field observations indicate that the maximum keel depth is typically 3-5.5 times greater than the sail height (e.g. Melling and others, 1993; Bowen and Topham, 1996). Ridge-specific values of $\rho^{*}$ are therefore necessary to avoid overestimation of the thickness of ridges from IPS draft measurements. At the same time, the AEM data may also underestimate the thickness of deformed ice by assuming uniform ice conductivity and neglecting voids below the waterline that may interact with the secondary field (Reid and others, 2003; Pfaffling and others, 2007). With the thickness of pressure ridges gaining greater attention, primarily due to the hazard they pose to maritime operations, reducing these uncertainties will become increasingly important. Comparisons between coincident airborne and submarine measurements of ice thickness, in particular with the inclusion of accurate altimetry from an EM-bird, will likely be of great value in constraining more sophisticated models for treating deformed ice. This underscores the importance of coordinated observing networks such as SIZONet.

Through direct comparison of coincident and co-located time series, we show that there is good agreement between ice velocities measured through acoustic bottom tracking with an upward-looking ADCP and those determined through optical flow analysis of imagery of the upper 
surface of the ice acquired by a coastal radar system (Figs 7 and 8). This is the first independent validation of radarderived ice velocities that we are aware of and it demonstrates that surface radar can be an effective tool for quantitatively observing ice motion in the coastal zone. With the potential for greater temporal resolution, surface radar may provide a suitable alternative to bottom-moored ADCPs for measuring ice velocity in places where necessary infrastructure exists. Moreover, since they are able to provide data in real time, coastal radars represent an effective means of identifying certain ice-related hazards as they are happening and possibly before they occur.

\section{ACKNOWLEDGEMENTS}

This work was supported by the US National Science Foundation (awards ARC 0632398 and 0856867), the US Department of Homeland Security Center for Island, Maritime and Extreme Environment Security (CIMES) and by a Grant in Aid for Scientific Research from the Japanese Ministry of Education, Culture, Sports, Science and Technology (MEXT) (awards 20221001 and 23654163). We also thank the staff of $\mathrm{CH} 2 \mathrm{M}$ HILL Polar Services, the Barrow Arctic Science Consortium and UMIAQ for field support in Barrow. We are also grateful to the North Slope Borough Department of Wildlife Management for use of their boat and assistance from their staff.

\section{REFERENCES}

Arctic Council (2009) Arctic marine shipping assessment 2009 report (AMSA). Arctic Council, Trømsø

Belliveau DJ, Bugden GL, Eid BM and Calnan CJ (1990) Sea ice velocity measurements by upward-looking Doppler current profilers. J. Atmos. Ocean. Technol., 7(4), 596-602 (doi: 10.1175/1520-0426(1990)007<0596:SIVMBU>2.0.CO;2)

Bowen RG and Topham DR (1996) A study of the morphology of a discontinuous section of a first year arctic pressure ridge. Cold Reg. Sci. Technol., 24(1), 83-100 (doi: 10.1016/0165-232X(95) 00002-S)

Doble MJ, Skouroup H, Wadhams P and Geiger CA (2011) The relation between Arctic sea ice surface elevation and draft: a case study using coincident AUV sonar and airborne scanning laser. J. Geophys. Res., 116(C8), C00E03 (doi: 10.1029/ 2011JC007076)

Druckenmiller ML, Eicken H, Johnson MA, Pringle DJ and Williams CC (2009) Toward an integrated coastal sea-ice observatory: system components and a case study at Barrow, Alaska. Cold Reg. Sci. Technol., 56(2-3), 61-72 (doi: 10.1016/j.coldregions. 2008.12.003)

Druckenmiller ML, Eicken H, George JC and Brower L (2010) Assessing the shorefast ice: Iñupiat whaling trails off Barrow, Alaska. In Krupnik I, Aporta C, Gearheard S, Laidler GJ and Holm LK eds SIKU: knowing our ice: documenting Inuit sea ice knowledge and use. Springer, Dordrecht, 203-228

Eicken H, Shapiro LH, Gaylord AG, Mahoney A and Cotter PW (2006) Mapping and characterization of recurring spring leads and landfast ice in the Beaufort and Chukchi seas. (OCS Study MMS 2005-068) Minerals Management Service, US Department of the Interior, Anchorage, AK

Forsström S, Gerland S and Pedersen CA (2011) Thickness and density of snow-covered sea ice and hydrostatic equilibrium assumption from in situ measurements in Fram Strait, the Barents Sea and the Svalbard coast. Ann. Glaciol., 52(57 Pt 2), 261-270 (doi: 10.3189/172756411795931598)
Fowler C (2003) Polar Pathfinder Daily 25km EASE-Grid Sea Ice Motion Vectors. National Snow and Ice Data Center, Boulder, CO. Digital media: nsidc.org/data/nsidc-0116

Fukamachi Y, Mizuta G, Ohshima KI, Toyota T, Kimura N and Wakatsuchi M (2006) Sea ice thickness in the southwestern Sea of Okhotsk revealed by a moored ice-profiling sonar. J. Geophys. Res., 111(C9), C09018 (doi: 10.1029/2005JC003327)

George JC, Huntington HP, Brewster K, Eicken H, Norton DW and Glenn R (2004) Observations on shorefast ice dynamics in Arctic Alaska and the responses of the Iñupiat hunting community. Arctic, 57(4), 363-374

Gordon RL (1996) Acoustic Doppler current profiler principles of operation: a practical primer, 2nd edn. RD Instruments, San Diego, CA

Haas C, Lobach J, Hendricks S, Rabenstein L and Pfaffling A (2009) Helicopter-borne measurements of sea ice thickness, using a small and lightweight, digital EM system. J. Appl. Geophys., 67(3), 234-241 (doi: 10.1016/j.jappgeo.2008.05.005)

Haas C, Hendricks S, Eicken H and Herber A (2010) Synoptic airborne thickness surveys reveal state of Arctic sea ice cover. Geophys. Res. Lett., 37(9), L09501 (doi: 10.129/ 2010GL042652)

Hansen E and 7 others (2013) Thinning of Arctic sea ice observed in Fram Strait: 1990-2011. J. Geophys. Res., 118(C10), 5202-5221 (doi: 10.1002/jgrc.20393)

International Organization for Standardization (ISO) (2010) Petroleum and natural gas industries - Arctic offshore structures. (ISO/ DIS 19906) International Organization for Standardization, Geneva

Jones JM (2013) Landfast sea ice formation and deformation near Barrow, Alaska: variability and implications for ice stability. (MS thesis, University of Alaska Fairbanks)

Kurtz NT and 6 others (2009) Estimation of sea ice thickness distributions through the combination of snow depth and satellite laser altimetry data. J. Geophys. Res., 114(C10), C10007 (doi: 10.1029/2009JC005292)

Kwok R and Cunningham GF (2008) ICESat over Arctic sea ice: estimation of snow depth and ice thickness. J. Geophys. Res., 113(C8), C08010 (doi: 10.1029/2008JC004753)

Kwok R, Cunningham GF and Hibler WD III (2003) Sub-daily sea ice motion and deformation from RADARSAT observations. Geophys. Res. Lett., 30(23), 2218 (doi: 10.1029/2003GL018723)

Laxon SW and 14 others (2013) CryoSat-2 estimates of Arctic sea ice thickness and volume. Geophys. Res. Lett., 40(4), 732-737 (doi: 10.1002/grl.50193)

Mahoney A, Eicken H and Shapiro L (2007) How fast is landfast sea ice? A study of the attachment and detachment of nearshore ice at Barrow, Alaska. Cold Reg. Sci. Technol., 47(3), 233-255 (doi: 10.1016/j.coldregions.2006.09.005)

Mahoney AR and 6 others (2012) Mapping and characterization of recurring spring leads and landfast ice in the Beaufort and Chukchi seas. (OCS Study BOEM 2012-067) Washington DC

Melling H, Topham DR and Riedel D (1993) Topography of the upper and lower surfaces of 10 hectares of deformed sea ice. Cold Reg. Sci. Technol., 21(4), 349-369 (doi: 10.1016/0165232X(93)90012-W)

Melling $\mathrm{H}$, Johnston PH and Riedel DA (1995) Measurements of the underside topography of sea ice by moored subsea sonar. J. Atmos. Ocean. Technol., 12(3), 589-602 (doi: 10.1175/15200426(1995)012<0589:MOTUTO>2.0.CO;2)

Pfaffling A, Haas C and Reid JE (2007) A direct helicopter EM sea ice thickness inversion, assessed with synthetic and field data. Geophysics, 72(4), F127-F137 (doi: 10.1190/1.2732551)

Postberg F, Schmidt J, Hillier J, Kempf S and Srama R (2011) A saltwater reservoir as the source of a compositionally stratified plume on Enceladus. Nature, 474(7353), 620-622 (doi: 10.1038/nature10175)

Reid JE, Worby AP, Vrbancich J and Munro AIS (2003) Shipborne electromagnetic measurements of Antarctic 
sea-ice thickness. Geophysics, 68(5), 1537-1546 (doi: 10.1190/ 1.1620627)

Rohith MV, Jones J, Eicken H and Kambhamettu C (2013) Extracting quantitative information on coastal ice dynamics and ice hazard events from marine radar digital imagery. IEEE Trans. Geosci. Remote Sens., 51(5), 2556-2570 (doi: 10.1109/TGRS. 2012.2217972)

Schmidt C (2011) Despite data gaps, US moves closer to drilling in Arctic Ocean. Science, 333(6044), 812-813

Shapiro LH and Metzner RC (1989) Nearshore ice conditions from radar data, Point Barrow, Alaska. (Rep. UAG-R312) University of Alaska Fairbanks, Fairbanks, AK

Stroeve JC, Serreze MC, Holland MM, Kay JE, Maslanik J and Barrett AP (2012) The Arctic's rapidly shrinking sea ice cover: a research synthesis. Climatic Change, 110(3-4), 1005-1027 (doi: 10.1007/s10584-011-0101-1)
Thorndike AS, Rothrock DA, Maykut GA and Colony R (1975) The thickness distribution of sea ice. J. Geophys. Res., 80(33), 4501-4513 (doi: 10.1029/JC080i033p04501)

Timco GW and Frederking RMW (1996) A review of sea ice density. Cold Reg. Sci. Technol., 24(1), 1-6 (doi: 10.1016/0165232X(95)00007-X)

Wang M and Overland JE (2009) A sea ice free summer Arctic within 30 years? Geophys. Res. Lett., 36(7), L07502 (doi: 10.1029/2009GL037820)

Warren SG and 6 others (1999) Snow depth on Arctic sea ice. J. Climate, 12(6), 1814-1829 (doi: 10.1175/1520-0442(1999) $012<1814:$ SDOASI $>2.0$. CO; 2$)$

Williams SB and 6 others (2008) AUV-assisted surveying of relic reef sites. Proceedings of OCEANS 2008, 15-18 September 2008, Quebec City, QC. Institute of Electrical and Electronics Engineers, Piscataway, NJ, 1-7 